\title{
العلاقة بين اللغة العربية وعلم النحو
}

Nurul Musyafa'ah

Institut Agama Islam Sunan Giri Bojonegoro

Email: bintakholiq@gmail.com

$$
\begin{aligned}
& \text { الملخص:إن هذا الباب يبجث عن العلاقة بين اللغة العربية وعلم النحو وينعسم هذا الباب الى فصلين وهما } \\
& \text { الفصل عن اللغة العربية وخصائصها، ويليه الفصل الثانى حيث يذكر فيه حاجة اللغة العربية إلى النحو. كان هذا } \\
& \text { البحث يستخلدم التحليل النوعي بطريقة الدراسة المكتبية لجمع البيانات و الاستعلامات بمساعلة أنواع المواد التي } \\
& \text { توجد في المكتبة. اختارت الباحثة هذه الطريقة لإدراك المعلومات المتعلدة من مصادرها و تحقيق الوثائق التي تتعلق } \\
& \text { بالبيانات المطلوبة. يركز هدف التحقيق في المواد المكتوبة في الكتب أو النسخة أو الجريلة أو غير ذلك. والنتيجة } \\
& \text { عن هذا البحث هي النحو وظائف مهمة في حغظ سامة اللغة العربية من الغساد والاضطراب، تعنى } \\
& \text { لإعانة القراء لفهم المقروء وإعانة المتكلم لتعبير الكلام الصحيح ثم إعانة الكتاب للوصول الى الكتابة } \\
& \text { الصحيحة } \\
& \text { الكلمات الرئيسية: اللغة العببية، والنحو، الجملة. }
\end{aligned}
$$

كانت اللغة العربية فن العصر الجاهلي و عصر صدر الإسلام تعيش عيشة قوية مع أنه ليست لها قواعد و قوانين احتفظ بها العرب عن الخطاء في النطق و القراءة. و ذلك لأن العرب يتكلمون بلغتهم قائمة على الفطرة السليمة والسليقة المستقيمة، فلا يحتاجون إلى القواعد و القوانين. و إن قواعدهم للغتهم فطرة موروثة 
من أبائهم جيلا بعد جيل و حافظوها في نفوسهم. و أما البادية فقد بقيت اللغة خالصة حتى أخر القرن

وأما نشأة النحو العربى ترتبط ارتباطا وثيقا بمحاولة المسلمين لصيانة القرأن الكريم من التحريف، و لحفظ اللغة العربية من الفساد و الاضطراب. و البحث فن نشأة قواعد اللغة العربية يعتبر من أصعب البحوث فيه و ذلك لأسباب منها: لأن هذا العلم قديم النشأة، و أن الروايات التى تحكي عن هذه النشأة كثيرا ما متضاربة.

ومن أهم الأسباب فن نشأته وجود اللحن في قراءة آيات الذكر الحكيم. بدأ انتشار اللحن بعد الفتوحات الإسلامية فن البلاد المجاورة بالباد العربية، مثل مصر و الشام و العراق و فارس. فتلك الفتوحات تؤدى إلى أن يختلط مسلموا العرب بالأعاجم. فأخذ الأعاجم يتكلمون باللغة العربية في البلاد المفتوحة حيث يتكلم الاعاجم بها شيئا فشيئا حسب قدرقم حتى غلبت ما عداها. و من ناحية أخرى فسدت فصاحة اللغة و ظهر اللحن عند نطق تلك اللغة و عند قراءة القرأن الكريم. هكذا كان الإسلام و الفتح سببا في انتشار اللغة العربية مهما قد أتت بها أشياء لها خطرها, و منها اختلاط العرب بالأعاجم كما مرّ ذكره. والنتيجة من هذا الاختلاط أخذ الفساد يدبّ فن التكلم بين العرب و العجم و ظهر اللحن فيه. فوعى المسلمون و بادروا المى اتخاذ الوسائل لحفظ لغتهم العربية و درء خطرها. فظهر في أرض العراق إهتمام عظيم في وضع علم النحو حيث يجفظ به سلامة اللغة العربية من الفساد و الاضطراب. لتحقيق ما سبق صممت الباحثة أن يقدم بحثا علميا تحت الموضوع " العلاقة بين اللغة العبية وعلم النحو " ترجوا الباحثة أن تكون نتيجة البحث دافعة للمشتغلين باللغة العربية ليعرفوا العلاقة بين اللغة العربية وعلم النحو حيث كان لهم فضلهم ومساهمتهم في بناء اللغة العربية وقواعدها.

$$
\begin{aligned}
& \text { ' أحمد حسن الزيات. تاريخ الأدب العربي (جهول الطباعة) ط 25. ص } 205
\end{aligned}
$$

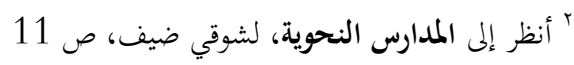




\section{ب. منهج البحث}

هذا البحث يستخدم التحليل النوعي و يأتي على طريقة الدراسة المكتبية و هي على صورة بسيطة تعني طريقة سلكتها الباحثة لجمع البيانات و الاستعلامات بمساعدة أنواع المواد التي توجد في المكتبة. اختارت الباحثة هذه الطريقة لإدراك المعلومات المتعددة من مصادرها و تحقيق الوثائق التي تتعلق بالبيانات المطلوبة. يركز هدف التحقيق في المواد المكتوبة في الكتب أو النسخة أو الجريدة أو غير ذلك. أما طريقة جمع البيانات التي سلكتها الباحثة فهي ما يلي : n أ. جمع الكتب التي تحتوي البيانات أو المعلومات المطلوبة لأداء البحث. ب. قراءة المواد التي تتعلق بالموضوع قراءة عميقة و اعطاء العلامة في كل. ج. نقل البيانات إلى قرطاس خاص مع ذكر اسم الكتاب و اسم المؤلف و الطبعة و مكان الطباعة وسنة الطباعة و صفحة المنقول. د. ترتيب البيانات المنقولة وفق الخطة التي أعدت من قبل. فطريقة تحليل البيانات تعني بعد أن اجتمعت المواد المطلوبة، فيأتى بعد ذلك إجراء تحليل المواد و هي كالخطوات الأتية : أ. تخفيض البيانات (Reduksi Data)، و هو الخطوة لتحليل المواد بطريقة التلخيص و التقسيم و اختيار الأمور المهمة و البحث عن الموضوع و تعيين المخططات׳ّ.

ب. استعراض البايانات (Display Data)، و هو تقديم البيانات أو الحقائق على سبيل الاختصار و معبرة بتعبير قصصي Sugiono. Metode Penelitian Kualitatif dan Kuantitatif, (Bandung: Alfabeta, 2008) h. 427 
ج. خطوة تفسيرية (Interpretasi)، و هي خطوة تحليل المواد بطريقة تفسير المعنى عما حدث و الفهم من وراء

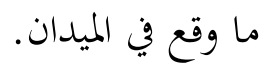
د. خطوة المقارنة، و ذلك بمقارنة بين شيئين اثنين من ناحية التشابه و التخالف في أمر أو أمور. هـ خطوة الاستناج (Conclusion)، و هى أخذ النتيجة، كما بكثه في الموضوع و النتيجة في البحث النوعي عبارة عن أجوبة القضايا عن موضوع البحث.

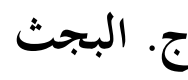

\section{| (اللغة العربية وخصائصها}

اللغة هى شئ موروث من جيل الى جيل بعده، وتختلف بغيرها من الموروثة الأخرى

كالاموال والحرث والأنعام وغيرها. تكون اللغة زادا للانسان لتيسير المعاملة والمخالطة بغيره. من التعريف السابق يظهر أن اللغة تصممت أربعة عناصر أساسية تمثل فن نفس الوقت أربع قضايا يتناولها مفهوم اللغة وهى : أصوات ووظيفة اللغة من حيث اها تعبير. والطابع الإجتماعى للغة وارتباطها بالجماعة اللغوية والطابع العقلى النفسى الذى يتمثل في علاقة الفكر باللغة. 
اما العنصر الأول الذى اشتمل عليه تعريف ابن جنى فيتمثل في تأكيده على الطبيعة الصوتية اللغوية للغة. وهذا مثل ما قرره علماء اللغة المحدثون في تعريفاتم. مثل سيمون بوتر (Ferdinand D Sausser) وجون كارول (John Carrol) وفردناند دى سوسير (Simon Potter) العنصر الثانى الذى اشتمل عليه تعريف ابن جنى للغة فيتمثل في إثارته الى وظيفة اللغةف أها تعبير. وذلك فن تعريفه للغة بأها اصوات يعبر بها كل قوم عن اغراضهم. ونجد أن ابن جنى يتفق مع غالبية علماء اللغة المحدثين الذين يرون أن وظيفة اللغة هى التعبير. وذلك شل ما ذهب اليها كل من سيمون وكارول، غير أفما استعملا عبارة التواصل او الاتصال ' (Communication)

العنصر الثالث الذى اشتمل عليه تعريف ابن جنى للغة فيتمثل فى إشارته الى الطابع الإجتماعى للغة، غير أنه استخدم لفظ القوم بدلا من لفظ المجتمع، وذلك لان هذا الاصطلاح الأخير، ربما لم يكن معروفا في ذلك الوقت بنفس الدلالة.

والعنصر الرابع الذى اشتمل عليه تعريف ابنى جنى السابق حيث يشير الى قضية شغلت

عقول اللغويين والفلاسفة وعلماء النفس وهى العلاقة بين الاصوات والاغراض أو بين الفكر واللغة.

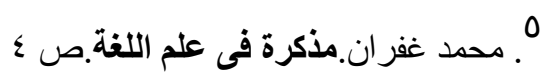

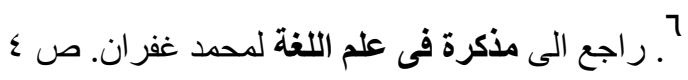


واذا بنينا على ما عرّفه ابن جنى فمفهومها، اصوات يعبر بها العرب عن اغراضهم. وعلى وجه خاص فقد عرّف الاسكندرى بأها : لغة امة العرب القديمة العهد الشائعة الذكر التى تسكن الجزيرة المنسوبة اليها فن الطرف العرى من اسياً. ومن خصائص البارزة التى تمتاز بها اللغة العربية، ما بدت في الأصوات اللغوية وفى سعة الاشتقاق. فيما يأتى بيان كل واحد منها:

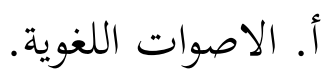

ان دراسة الاصوات فن العربية وفى غيرها، من الدراسات المهمة التى يتوقف عليها فهم كثير من الظواهر اللغوية. ومما وضعه الخليل إعادة ترتيب الحروف المحائية على أساس من ترتيب الجهازالصوتي من الحنجرة الى الشفتين كما يأتي : الهمزة والهاء والعين والحاء والخاء والغين والكاف والقاف والجيم والشين والضاد والصاد والسين والزاى والطاء والدال والتاء والظاء والذال والثاء والراء واللام والنون والفاء والباء والميم والواو والياء والألف^

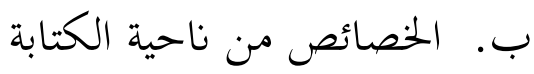
ويعرف فن بعض الأحرف العربية بالتنقيط أى نقط الإعجام. ووظيفته التمييز بين الاحرف المتشاجة بصورة الرسم، مثل بين حرف : ب و ت و ث، وبين ج و ح و خ، وبين ع و غ، وبين

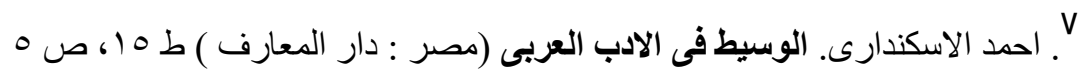

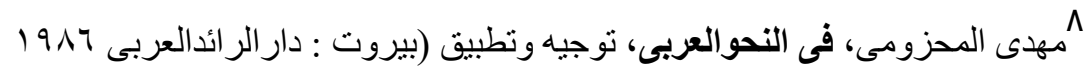


ف و ق. لولا النقط في بعض الحروف المتشابهة لا لتبس بين حرف واخر، وذلك مما أدى الى قراءة

$$
\text { الحرف على غير حقيقته.. - ملي }
$$

$$
\text { ج. الخصائص في سعة الاشتقاق }
$$

الإشتقاق من ناحية الاصطلاح فقد اعطى تعريفات عدة، منها اقتطاع فرع من اصل يدور

في تصاريفه حروف ذلك الأصل، وقيل إنه أخذ كلمة من اخرى بتغيير ما مع التناسب فن المعنى . ويشترط في الاشتقاق، اسما كان او فعلا بثلاثة أمور، وهى :

$$
\text { ا ـ. ان يكون له اصل، فإن المشتق فرع مأخوذ من لفظ اخر. }
$$

r. ان يناسب المشتق الأصل في الحروف، والمعتبر المناسبة بين الأصالة والفرعية فن جميع

$$
\text { الحروف الأصلية. }
$$

r. المناسبة فن المعنى سواء لم يتفقا فيه أو اتفقافيه، وذلك الاتفاق بأن يكون في المشتق

$$
\text { د. الخصائص من ناحية الاعراب الاصل. }
$$

يعتبر الإعراب من الخصائص التى امتازت بها اللغة العربية عن غيرها من اللغات. وأما

الإعراب فن اللغة مصدر الفعل، اعرب - يعرب - اعرابا بمعنى الإبانة والافصاح والايضاح. أما

في الاصطلاح فهو تعير العلامة التى في اخر اللفظ بسبب تغير العوامل الداخلة عليه، وما

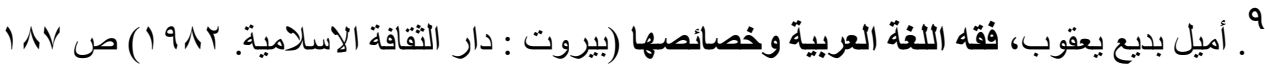


يقتضيه كل عامل ' . ويقابله البناء، وهو ما يلزم اخره حالة واحدة. فلا يتغير وإن تغيرت العوامل

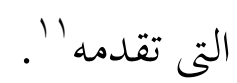

والأمثلة التى توضح دور الاعراب في الجملة العربية، نحو " ما أحسن الرجل ". كانت هذه

الجملة لم تبين المعنى المحدد، اذا كانت خالية من الاعراب. وقد تأتى بمعنى الاستفهام اذا قرئت : ما احسن الرجل ؟ او بمعنى التعجب فن النحو : ما احسن الرجل، بفتح النون واللام. او بمعنى النفى، في النحو : ما احسن الرجل، بفتح النون وضم اللام. فتغير معناها بتغير اعرابها. وكذا نحو : لا تأكل سمكا وتشرب لبنا، بجزم تشرب بمعنى النهى عن كل منهما. فإذا نصبت تشرب، يكون النهى عن الجمع بينهما. ای لا يكون منك اكل السمك مع شرب لبن. أما اذا رفعت تشرب فيكون النهى منصبا على اكل السمك مع اباحة شرب اللبن. ومنها الاية الكريمة : أن الله برئ من المشركين ورسوله '. ان قرئت بجر رسوله، تؤدى إلى الكفر، وإن قرئت برفعه رسوله أو نصبه تؤدى المى المعنى المستقيم. لانه معطوف المى لفظ الجلالة. والايات الكريمة التى تختلف معانيها باختلاف حركاتما كثيرة جدا. ولا تعرف لغة من لغات البشرية مثل هذه الدقة والاطراد في ظاهرة من ظواهرها؟”. ץ. اجة اللغة العربية المى النحو كان النحو من اول وضعه يقصد لحفظ سلامة اللغة العربية من الفساد والاضطراب. وظهوره كرد فعل لمظاهر اللغة العربية، حيث فشت فيها الألحان بين ألسنة المسلمين عربهم وعجمهم. فقام

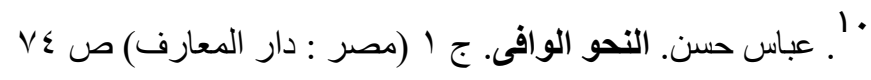

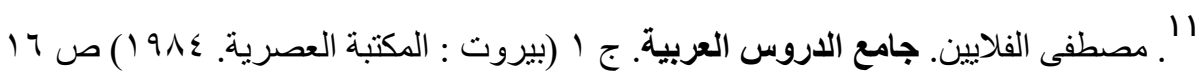

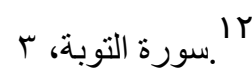

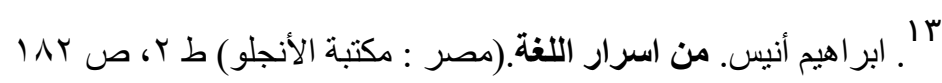


إمامهم بإصلاح ما حدث فيها من الاخطاء والالحان بين الأمة، فوضع القواعد التى تتعلق باللغة العربية ليعتمد عليها الأمة وليرجعوا إليها إن بدت بينهم المسائل اللغوية. وقد حدث ذلك في القرن الثانى الهجرى وما بعده. والجملة في النحو وظائف مهمة في حفظ سلامة اللغة العربية من الفساد والاضطراب، وعلى صورة تفصيلية تأتى وظائفها ما يلى، وهى لإعاتة القراء لفهم المقرؤ فهما جيدا. ولإعانة المتكلم لتعبير الكلام الصحيح ولإعانة الكتاب لتعبير ماكتب بعبارة صحيحة. وفيما يلى بيان كل واحد من تلك الوظائف : 1. إعانة القراء لفهم المقروء

أى من كان اذا اراد أن يقرأ النصوص العربية فلزم عليه ان يراعى قواعدها. وقد دونت قواعد اللغة العربية في علم النحو، وهذا الفن تضمن الضوابط والنظم التى تتعلق بالكلمات العربية حينما كانت مركبة جملا. فقرأ سورة البراءة، فلما وصل الى الاية : أن الله برئ من المشركين ورسوله بكسر اللام فن رسوله فقال الاعرابى : أو قد برئ الله من رسوله ان يكن الله بريئا من رسوله فأنا أبرأ منهء'. وقد يأتى الخبر مقدما على المبتدأ، وهذا النمط يأتى كثيرا في العبارات العربية نثرا كان ام شعرا، نخو : ما خالق الا الله، ونخو قول نصيب : اهابكِ اجلا لا وما بك قدرة \# على ولكن ملءُ عين حبيبها 10

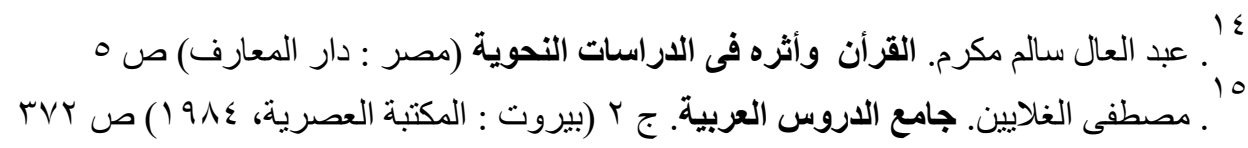


وقد ترد في العبارات العربية معمولات، بدون ذكر عواملها كنحو : اهلا وسهلا، وسمعا

وطاعة، وقوله تعالى : ولسليمان الريح غدوها شهر ورواحها شهر، وكحديث الرسول (ص.م) : الناس مجزيون بأعمالهم إن خيرا فخير وان شرا فشر. اذا اهتممنا هذه العبارات عرفنا المعمولات وليس معها ذكر العوامل. فطبعا هذه الأمثلة تخالف المألوف لأن في العربية جرت عليها نظرية العوامل والمعمولات. نعنى بهذه، ان لكل مرفوع رافع ولكل منصوب ناصب ولكل بجرور ما يجره كما كان لكل مجزوم ما يجزمه. فالكلمات اهلا وسهلا وسمعا وطاعة، والكلمة الريح في الاية والكلمة خيرا وشرا في الحديث، كانت خالية من العوامل الملفوظة. واذا راجعنا المى علم النحو لوجدنا الجواب من تلك الظواهر اللغوية، وهذه العبارات لا تخالف علم النحو، لان العامل إما ظاهر وإما مقدر. واذا كان الامر كذلك فلكل واحدة من الكلمات السابقة عواملها وبها يعرف معناها. فأهلا وسهلا. مفعول به وأصله عند سيبويه اصبت اهلا ونزلت سهلا" '. والتعبير سمعا وطاعة جرى في الكلام العرب بدلا من التلفظ بفعله ومعناه اسمع واطيع '. ونصب الكلمة "الريح" في الاية ولسليمان الريح، لأنه مفعول به اى سخرنا الريح عند ابى عمر بن العلاء`'. اما سبب نصب خيرا وشرا في الحلديث إن خيرا فخير وإن شرا فشر، على اهما خبر كا ن المحذوفة. واصل العبارة عند الغلايينى ان كان عملهم خيرا فجزاؤهم خير وان كان عملهم شرا فجزاؤهم شر '1 . r إعانة المتكلم لتعبير الكلام الصحيح

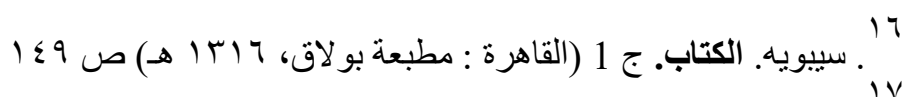

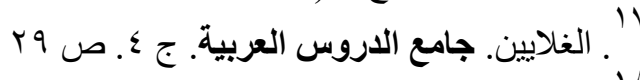

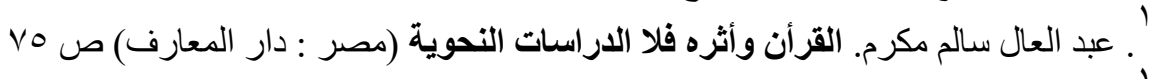

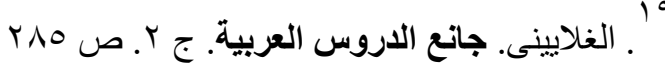


مع ان اللغة العببية لغة لازمتها قواعدها في كل صيغها، الا وهى علم النحو. واذا كانت اللغة العربية خالية من نظام نهوى فما هى إلا لغة همجية، وربما سيؤدى التعبير المى اخطاء مضاعفة.

$$
\text { قال الشيح يجي شريف الدين العمرطى : }
$$

والنحو أولى اولا أن يعلما \# اذ الكلام دونه لن يفهما‘r

بناء على ما سبق ذكره، فينبغى للمتكلم او الكاتب - أراد أم لم يرد - أن يكون ذا مقدرة في

علم النحو. ويطبقه فن تعبيره حتى يكون تعبيره صحيحا ومعناه مستقيما. r. إعانة الكتاب للوصول الى الكتابة الصحيحة

ان الكتابة صورة من الكلمات او العبارات الملفوظة، فصحة الكتابة من الأمور المهمة فن اللغة العربية لأغها دليل ما اراده الكاتب ومعنى العبارات. والكتابة العربية احتاجت كثيرا الى الاهتمام الخاص والدقة العالية لأن الخطاء فيها - وان كان قليلا - يؤدى الى الخطاء في المعنى، وذلك لكون اللغة العربية ذات خصائص امتازت بها عن غيرها من اللغات. فيلزم على الكاتب ان يراعى ما بجب مراعاته فن التعبير، كإعراب الكلمات من رفع أو نصب أو جر أو جزم، او بناء الكلمات، او ما كان مقصورا منها او ممدودها، او ما كان مشددا منها او غير مشدد، او وضوح صفة حروفها أو غير 
لا يخفى علينا ان اللغة العربية هى احدى اللغة ذات طوابع خاصة. ومن أبرز طوابعها كثرة المباحث التى تتعلق بقواعدها، كمباحث الاعراب حيث لم توجد في غيرها، وكثرة انواع الضمائر ولكل واحد منها موقع خاص ووظيفة خاصة. والطابع الإجتماعى مما أحس الناس بالحاجة الى التفاهم فيما بينهم.

فعلم النحو يعتبر من العلوم العربية المهمة، لأنه يلعب دورا هاما فن اللغة العربية. يظهر دور النحو فيها لأنه الة للوصول الى تركيب الجمل الصحيحة، والة للوصول الى القراءة الصحيحة والى ادراك المعنى الصحيح من الجمل العربية. ثم أن علم النحو وظائف مهمة في حفظ سلامة اللغة العربية من الفساد والاضطراب، تعنى لإعانة القراء لفهم المقروء وإعانة المتكلم لتعبير الكلام الصحيح ثم إعانة الكتاب للوصول الى الكتابة الصحيحة

\section{قائمة المراجع}

حسان. عباس. اللغة والنحو بين القديم والحديث. دار المعارف. مصر. 779 ام. الزبيدى. أبو بكر بن حسن. طبقات النحويين واللغويين. دار المعارف. مجهول السنة. الزيات. احمد حسن. تاريخ الادب العربى. مجهول المطبعة والسنة. ضيف. شوقى. الدكتور. المدارس النحوية. دار المعارف. القاهرة. r ب ا م. 
العلاقة العلم النحو

مكرم. عبد العال سالم. القرأن واثره فى الدراسات النحوية. دار المعارف. مصر. مجهول السنة.

$$
\text { الغلايينى. مصطفى. جامع الدروس العبية. ج r. }
$$

البيجورى، ابراهيم. فتح رب البرية. سورابايا : مكتبة ومطبعة احمد بن سعد بن نبهان

ابراهيم أنيس. من اسرار اللغة. مصر .مكتبة الأنجلو 